\title{
Pesticide Residues in Honey from the Major Honey Producing Forest Belts in Ghana
}

\author{
Godfred Darko, ${ }^{1}$ Jonah Addai Tabi, ${ }^{1}$ \\ Michael Kodwo Adjaloo, ${ }^{2}$ and Lawrence Sheringham Borquaye ${ }^{1}$ \\ ${ }^{1}$ Department of Chemistry, Kwame Nkrumah University of Science and Technology, Kumasi, Ghana \\ ${ }^{2}$ Technology Consultancy Centre, Kwame Nkrumah University of Science and Technology, Kumasi, Ghana \\ Correspondence should be addressed to Godfred Darko; gdarko.sci@knust.edu.gh
}

Received 2 May 2017; Accepted 2 July 2017; Published 16 August 2017

Academic Editor: Chunrong Jia

Copyright (C) 2017 Godfred Darko et al. This is an open access article distributed under the Creative Commons Attribution License, which permits unrestricted use, distribution, and reproduction in any medium, provided the original work is properly cited.

\begin{abstract}
Concentrations of pesticides residues in honey sampled from the major honey producing forest belts in Ghana were determined. Samples were purposively collected and extracted using the QuEChERS (Quick, Easy, Cheap, Effective, Rugged, and Safe) method and analysed for synthetic pyrethroids, organochlorine, and organophosphate pesticide residues. Aldrin, $\gamma-\mathrm{HCH}, \beta$ - $\mathrm{HCH}$, Eendosulfan, cyfluthrin, cypermethrin, deltamethrin, permethrin methoxychlor, SDDT, chlorpyrifos, fenvalerate, malathion, dimethoate, and diazinon were all detected at the concentration of $0.01 \mathrm{mg} / \mathrm{kg}$, while cyfluthrin and permethrin were detected at mean concentrations of 0.02 and $0.04 \mathrm{mg} / \mathrm{kg}$, respectively. All the pesticide residues detected were very low and below their respective maximum residue limits set by the European Union. Hence, pesticide residues in honey samples analyzed do not pose any health risk to consumers.
\end{abstract}

\section{Background}

Honey, the sweet and viscid fluid, which is produced by honeybees from the nectar of flowers, contains significant amounts of mineral matter, vitamins, and enzymes [1]. With respect to carbohydrates, honey is mainly fructose (about $38.5 \%$ ) and glucose (about 31.0\%) [2] and is known to be a healthier nutritional choice than sugar $[3,4]$. However, the specific composition of any batch of honey and contaminants present is dependent on the crops from which the nectar was sourced and the surroundings of the beehive. Honey is widely used for both nutritional and medicinal purposes and it is known to have therapeutic actions against infections, wounds, and cancers [5]. It has been used to treat cough and sore throat, ulcer, earache, measles, and eye diseases [6]. It is consumed, worldwide, as food or medicine. It is known that feeding infants with honey helps to improve their memory and growth, reduce anxiety, and enhance the children's performance as they grow in life [7]. Honey is also used in cosmetics and as a natural sweetener in food manufacturing.
While the nutritional value and quality aspects of honey are important, assurance of its chemical safety is critical to consumer acceptance. The health and nutritional benefits of honey are reduced if they are contaminated with toxic chemicals such as residues of pesticides [8] and other environmental contaminants. Honey is prone to contamination from the environment as trace amounts of pollutants, including residues of pesticides, brought into the hive by the honeybee get concentrated during processing of the honey.

Pesticides are extensively used in Ghana [9], mainly for agriculture and disease control. While the use of the synthetic pyrethroids and carbamates as insecticides, weedicides, and fungicides is on the increase, the use of the organochlorines (mostly as insecticides on cash crops) has drastically reduced since their ban in 1999 [10]. However, residues of organochlorine pesticides continue to be detected in environmental samples and food items [11, 12] due to their persistence in the environment and illegal use. Even though the newer generation pesticides (synthetic pyrethroids, organophosphorus, and carbamates) are not as persistent as the first generation organochlorines, they are much more acutely toxic. Residues 
of organophosphorus pesticides have been detected in fruits and vegetables sold on the Ghanaian market [9].

All pesticides are toxic and several of them are potential carcinogens which may cause chromosomal abrasions [13]. Pesticides are also known to cause changes in the endocrine [14], the reproductive [15-17], and the nervous systems [18, 19]. Beekeeping is being promoted nation-wide, as a source of additional income for farmers. Therefore, monitoring of pesticide residues in the commodity is essential to ensure its quality and safety. However, there is no published data on the extent of pesticide contamination in honey in the country. Hence, this work determined the concentrations of pesticides residues in honey in the major honey producing forest belts in Ashanti, Brong-Ahafo, and Western regions of Ghana. Therefore, this study gives the baseline and the first ever reported data on the levels of pesticide residues in honey from Ghana.

\section{Materials and Methods}

2.1. Sampling. Honey samples were purposively collected from the major honey producing forest belts in Ashanti, Brong-Ahafo, and Western Regions of Ghana (Figure 1). All the sites are located in agricultural farmlands where various pesticides are applied continuously to either control insects or weeds. Honey from both wild forest and beekeepers was collected from February to June 2014 within the harvesting season. Protective gowns were worn and smoke from fire was used to drive away the honeybees prior to sample harvesting. After harvesting, the honey was squeezed from the wax, followed by filtration to remove debris. In all, a total of 45 honey samples consisting of 30 from the wild forest and 15 from domesticated beehives were obtained. About $500 \mathrm{~mL}$ of each sample was placed in labeled plastic containers and sent to the laboratory for analysis. All samples were kept at ambient temperature until the analysis.

2.2. Extraction. All reagents used were of analytical grade and were used as obtained without further purification. Samples were extracted using the Quick, Easy, Cheap, Effective, Rugged, Safe (QuEChERS) multiresidue method for the analysis of pesticide residues in low fat matrix [20-22]. A $5 \mathrm{~g}$ portion of homogenized honey sample was spiked with $100 \mu \mathrm{L}$ internal standard, mixed with $10 \mathrm{~mL}$ of ultrapure water (resistivity 18.2 $\mathrm{M}^{\prime} \Omega$ ) and homogenized by shaking to reduce its viscosity and facilitate its handling. The sample was mixed with $10 \mathrm{~mL}$ of acetonitrile (Sigma Aldrich, St. Louis, MO, USA) and subjected to extraction by shaking for $3 \mathrm{~min}$. A mixture of salts composed of $1 \mathrm{~g}$ sodium chloride, $1 \mathrm{~g}$ disodium hydrogen citrate sesquihydrate, $0.5 \mathrm{~g}$ trisodium citrate dehydrate, and $4 \mathrm{~g}$ magnesium sulphate anhydrous (all from M\&B Chemicals, New Delhi, India) were added to the mixture and vortexed for 3 mins for extraction with separation.

The organic phase was separated from the inorganic phase after centrifugation at $3000 \mathrm{rpm}$ for 5 mins. The supernatant was collected and the residue was reextracted with $10 \mathrm{~mL}$ of the solvent. The extract was transferred into a singleuse polypropylene centrifuge tube, which contains $25 \mathrm{mg}$ primary-secondary amine (PSA) and $150 \mathrm{mg} \mathrm{MgSO}_{4}$ (Sigma Aldrich, St. Louis, MO, USA). The tube was vortexed for $1 \mathrm{~min}$ followed by centrifugation at $3000 \mathrm{rpm}$ for 5 mins. After the centrifugation, the cleaned extract was transferred into a screw cap vial and the $\mathrm{pH}$ adjusted to 5 using $5 \%(\mathrm{v} / \mathrm{v})$ formic acid solution in acetonitrile [23-27]. The $\mathrm{pH}$-adjusted extracts were filled into vials for gas chromatography. The innovation in this method lies in the fact that it combines the extraction and clean-up processes into one-step, thereby reducing cross-contamination and increasing throughput [28].

2.3. Gas Chromatography. Analysis was carried out on a Varian CP-3800 gas chromatograph (Brescia, Italy) with a CombiPAL autosampler, an electron capture detector (ECD) for organochlorine and synthetic pyrethroids pesticides as well as pulse flame photometric detector (PFPD) for organophosphorus pesticides.

2.4. Chromatographic Conditions for Organochlorine and Synthetic Pyrethroids. Separation of analytes was achieved on a Varian capillary column $(30 \mathrm{~m}+10 \mathrm{~m}$ EZ Guard $\times 0.25 \mathrm{~mm}$ internal diameter fused silica capillary coated with VF-5ms, $0.25 \mu \mathrm{m}$ film). The carrier gas was nitrogen (99.999\% purity) at a flow rate of $1 \mathrm{~mL} / \mathrm{min}$. Oven temperature was maintained initially at $70^{\circ} \mathrm{C}$ for $2 \mathrm{~min}$ and increased at $25^{\circ} \mathrm{C} / \mathrm{min}$ to $180^{\circ} \mathrm{C}$ then at $5^{\circ} \mathrm{C} / \mathrm{min}$ to $300^{\circ} \mathrm{C}$. The injection volume was $1 \mu \mathrm{L}$, injected in splitless mode at an injection temperature of $270^{\circ} \mathrm{C}$, whilst the ECD detector was maintained at $300^{\circ} \mathrm{C}$.

2.5. Chromatographic Conditions of Organophosphorus Pesticides. Organophosphorus pesticides were separated on Varian capillary column $(30 \mathrm{~m} \times 0.25 \mathrm{~mm}$ internal diameter fused silica capillary coated with VF-1701ms, $0.25 \mu \mathrm{m}$ film) but detected and quantified on a PFPD kept at $280^{\circ} \mathrm{C}$. The carrier gas was nitrogen $(99.999 \%$ purity) at a flow rate of $2 \mathrm{~mL} / \mathrm{min}$. Oven temperature was maintained initially at $70^{\circ} \mathrm{C}$ for $2 \mathrm{~min}$ and increased at $25^{\circ} \mathrm{C} / \mathrm{min}$ to $200^{\circ} \mathrm{C} / \mathrm{min}$ and then at $20^{\circ} \mathrm{C} / \mathrm{min}$ to $250^{\circ} \mathrm{C}$. The injection volume was $1 \mu \mathrm{L}$, injected in splitless mode at an injection temperature of $270^{\circ} \mathrm{C}$.

2.6. Quality Control. Recovery test was carried out by spiking blank samples with $0.02 \mathrm{mg} / \mathrm{kg}$ standard mix. The fortified samples were then allowed to equilibrate for $30 \mathrm{~min}$ prior to extraction and analysis using the analytical methods described. The mean recovery values were calculated from the peak area obtained. Identification of analytes was by comparison with the retention times of the standards. Retention times were within \pm 0.20 min of the expected retention times [28]. Quantification of analyte concentrations were based on 5-point (ranging from 0.01 to $2.00 \mathrm{mg} / \mathrm{kg}$ ) calibration curves prepared. Blanks were routine run to check and correct instrument drifts and column contamination. All analyses were done in triplicate.

2.7. Limits of Detection. The detection limits of the GC coupled with either ECD or PFPD were determined for each pesticide by injecting serially diluted standard mix. Detection limits of the method were found by determining the lowest 


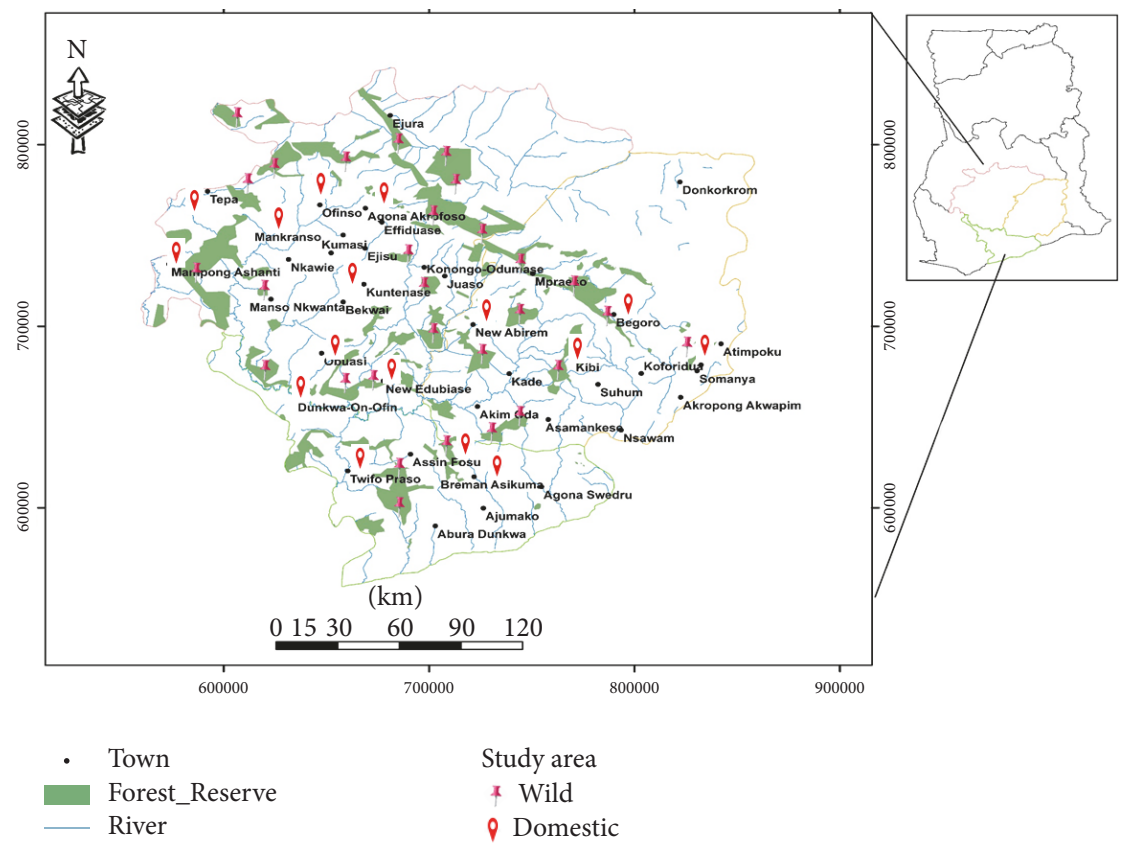

FIGURE 1: Map of Ghana showing the sampled zones in the Ashanti, Brong-Ahafo, and Western Regions.

concentrations of the residues in each of the matrices that could be reproducibly measured at the operating conditions of the GC using a signal-to-noise ratio of three. The detection and quantification limits for all the pesticide categories were found to be 0.01 and $0.04 \mathrm{mg} / \mathrm{kg}$, respectively. Blank analyses were also performed in order to check interference from the sample. All analyses were done in triplicate.

\section{Results and Discussion}

Recovery of the pesticides from the spiked samples was $90-99 \%$ for the organochlorines, $94-98 \%$ for the organophosphorus, and $89-96 \%$ for the synthetic pyrethroids. Recovery range of about $75-105 \%$ is deemed satisfactory in pesticide residue analysis $[26,27]$. Therefore, the recoveries achieved in this study were satisfactory indicating the extraction method used was selective and the analytical/instrument conditions were sensitive to the analytes.

In all, eleven pesticides (diazinon, chlorpyrifos, dimethoate, methoxychlor, malathion, aldrin, cyfluthrin, permethrin, fenvalerate, endosulfan, and DDT) were detected in the honey samples (Table 1). The concentrations found were mostly close to the limits of detection. Chlorpyrifos, dimethoate, methoxychlor, and malathion were the only organophosphorus detected but none of them had a concentration higher than the method's detection limits or the EU MRL. Cyfluthrin and permethrin were the most detected pyrethroids.

Samples from the Ashanti region had traces of dimethoate $(0.01 \mathrm{mg} / \mathrm{kg})$, endosulfan $(0.01 \mathrm{mg} / \mathrm{kg})$, fenvalerate $(0.01 \mathrm{mg} /$ $\mathrm{kg})$, and DDT $(0.01 \mathrm{mg} / \mathrm{kg})$. Concentration of $\sum \mathrm{DDT}$ was equal to the maximum residue limit (MRL) and thus warrants attention. The concentrations of fenvalerate and dimethoate were close to their MRL of $0.02 \mathrm{mg} / \mathrm{kg}$. Concentration of total endosulfan was, however, far less than the MRL of $0.05 \mathrm{mg} / \mathrm{kg}$. The forest honey samples showed a similar concentration pattern. Concentrations of cyfluthrin and methoxychlor were the same as their MRL and those of fenvalerate and permethrin were close to their MRL, whiles that of chlorpyrifos was lower than its MRL.

In the Brong-Ahafo region, diazinon, malathion, and permethrin were detected at concentrations higher than the method detection limits. However, the concentrations of malathion and permethrin $(0.01 \mathrm{mg} / \mathrm{kg})$ were lower than their MRL of 0.02 and $0.05 \mathrm{mg} / \mathrm{kg}$, respectively. The concentration of diazinon detected was the same as its MRL of $0.01 \mathrm{mg} / \mathrm{kg}$. In the forest samples, methoxychlor, aldrin, and cyfluthrin had the same concentrations as their MRL. Concentrations of the other residues detected (chlorpyrifos, permethrin, and endosulfan) were less than their MRL.

A similar case can be made for samples from the Western region. The concentrations diazinon and DDT detected were the same as their MRL $(0.01 \mathrm{mg} / \mathrm{kg})$. The concentration of malathion $(0.01 \mathrm{mg} / \mathrm{kg})$ was half its MRL. In the forest samples, aldrin $(0.01 \mathrm{mg} / \mathrm{kg})$ and cyfluthrin $(0.02 \mathrm{mg} / \mathrm{kg})$ had concentrations that were the same as their MRL. Whereas the concentration of permethrin $(0.04 \mathrm{mg} / \mathrm{kg})$ was close to its MRL $(0.05 \mathrm{mg} / \mathrm{kg})$, that of fenvalerate $(0.01 \mathrm{mg} / \mathrm{kg})$ was half its MRL. The forest samples recorded more pesticides than the beehive samples in all the regions. Of the pesticides detected, methoxychlor, chlorpyrifos, malathion, dimethoate, and diazinon belong to the organophosphorus group which is the most commonly used in the country.

Concentrations of organochlorine residues obtained in the current work are lower than the $0.09 \mathrm{mg} / \mathrm{kg} \mathrm{HCB}$ and $0.143 \mathrm{mg} / \mathrm{kg} \sum \mathrm{DDT}$ reported in honey samples from central Portugal [8]. They were also lower than the $0.30 \mu \mathrm{g} / \mathrm{g} \mathrm{HCB}$, 


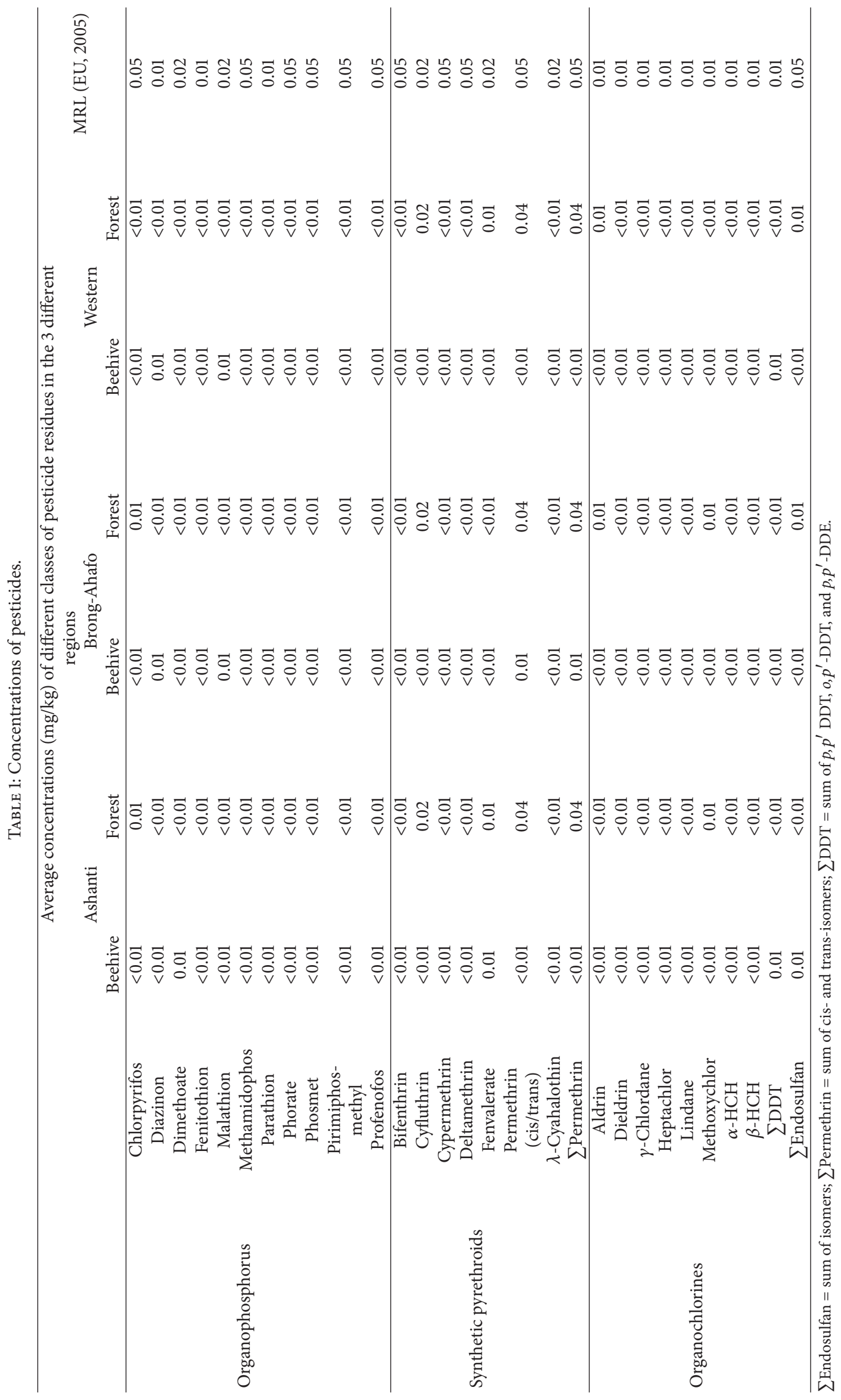


$0.05 \mu \mathrm{g} / \mathrm{g}$ chlordane, $0.04 \mu \mathrm{g} / \mathrm{g}$ heptachlor, $0.06 \mu \mathrm{g} / \mathrm{g}$ aldrin, and $0.36 \mu \mathrm{g} / \mathrm{g}$ total endosulfan reported for honey samples from Kahramanmaras, Turkey [29].

The ban on the use of DDT and restrictive use of other organochlorine pesticides such as endosulfan seem to have had a positive effect on environmental contamination even though traces of pesticide residues used in the past are still being detected in the environment. The presence of pesticide residues in the environment is a major cause of honeybee loss $[30,31]$.

According to European Union (EU) regulations, honey as a natural product must be free of any chemical contaminants and safe for human consumption [8]. On this basis, all the samples analyzed agreed with this regulation. However, since consumers are exposed to pesticides, usually in minute quantities, through several different food groups such as fruits, honey, and vegetables, monitoring the various food items becomes imperative in assessing environmental and human health risks. The significance of the study is that the practitioners of the honey industry could be made aware of the possibility of pesticide contamination in their honey products and thus take steps to avert it. Perhaps the relevant authorities could be involved in the regulation of pesticides use in the country.

\section{Conclusions}

QuEChERS method was satisfactorily applied for the extraction of pesticide residues in honey from major honey producing forest belts in Ghana. Aldrin, $\gamma-\mathrm{HCH}, \beta-\mathrm{HCH}$, $\sum$ endosulfan, cyfluthrin, cypermethrin, deltamethrin, permethrin methoxychlor, $\sum \mathrm{DDT}$, chlorpyrifos, fenvalerate, malathion, dimethoate, and diazinon were all detected but at very low concentrations. All the pesticide residues had concentrations lower than the recommended EU maximum residue limits. Hence, honey samples analyzed do not pose any health risk to the consumer as far as pesticide residues are concerned.

\section{Abbreviations}

\begin{tabular}{|c|c|}
\hline MRL: & Maximum residue limits \\
\hline EU: & European Union \\
\hline QuEChERS: & $\begin{array}{l}\text { Quick, Easy, Cheap, Effective, Rugged, and } \\
\text { Safe }\end{array}$ \\
\hline PSA: & Primary-secondary amine \\
\hline PFPD: & Pulse flame photometric detector \\
\hline $\mathrm{HCH}:$ & Hexachlorocyclohexanes \\
\hline GC-ECD: & $\begin{array}{l}\text { Gas chromatograph-electron capture } \\
\text { detector }\end{array}$ \\
\hline$\sum$ Permethrin: & $\begin{array}{l}\text { Sum of cis- and trans-isomers of } \\
\text { permethrin }\end{array}$ \\
\hline$\sum \mathrm{DDT}:$ & $\begin{array}{l}\text { 1,1,1-Trichloro-2,2-di-(4- } \\
\text { chlorophenyl)ethane. }\end{array}$ \\
\hline
\end{tabular}

\section{Conflicts of Interest}

The authors have read and understood journal's policy on declaration of interests and all authors declare that they have no competing financial, professional, or personal interests that might have influenced the performance or presentation of the work described in this manuscript.

\section{Authors' Contributions}

Godfred Darko, Michael Kodwo Adjaloo, and Lawrence Sheringham Borquaye conceived the study. Jonah Addai Tabi did the sampling and analysis under the guidance of Godfred Darko, Michael Kodwo Adjaloo, and Lawrence Sheringham Borquaye. Godfred Darko drafted the manuscript which was proofread by Michael Kodwo Adjaloo, Godfred Darko, and Jonah Addai Tabi. All authors approved the final manuscript.

\section{References}

[1] Y. R. Tahboub, M. F. Zaater, and T. A. Barri, "Simultaneous identification and quantitation of selected organochlorine pesticide residues in honey by full-scan gas chromatography-mass spectrometry," Analytica Chimica Acta, vol. 558, no. 1-2, pp. 6268, 2006.

[2] C. Blasco, P. Vazquez-Roig, M. Onghena, A. Masia, and Y. Picó, "Analysis of insecticides in honey by liquid chromatographyion trap-mass spectrometry: comparison of different extraction procedures," Journal of Chromatography A, vol. 1218, no. 30, pp. 4892-4901, 2011.

[3] A. R. Fontana, A. B. Camargo, and J. C. Altamirano, "Coacervative microextraction ultrasound-assisted back-extraction technique for determination of organophosphates pesticides in honey samples by gas chromatography-mass spectrometry," Journal of Chromatography A, vol. 1217, no. 41, pp. 6334-6341, 2010.

[4] N. Bilandžic, M. Dokić, M. Sedak et al., "Content of five trace elements in different honey types from Koprivnica-Križevci County," Slovenian Veterinary Research, vol. 49, no. 4, pp. 167175, 2012.

[5] N. S. Al-Waili and N. S. Boni, "Natural honey lowers plasma prostaglandin concentrations in normal individuals," Journal of Medicinal Food, vol. 6, no. 2, pp. 129-133, 2003.

[6] C. K. Zacharis, I. Rotsias, P. G. Zachariadis, and A. Zotos, "Dispersive liquid-liquid microextraction for the determination of organochlorine pesticides residues in honey by gas chromatography-electron capture and ion trap mass spectrometric detection," Food Chemistry, vol. 134, no. 3, pp. 1665-1672, 2012.

[7] A. Ajibola, J. P. Chamunorwa, and K. H. Erlwanger, "Nutraceutical values of natural honey and its contribution to human health and wealth," Nutrition and Metabolism, vol. 9, article 61, 2012.

[8] C. Blasco, C. M. Lino, Y. Picó, A. Pena, G. Font, and M. I. N. Silveira, "Determination of organochlorine pesticide residues in honey from the central zone of Portugal and the Valencian community of Spain," Journal of Chromatography A, vol. 1049, no. 1-2, pp. 155-160, 2004.

[9] G. Darko and O. Akoto, "Dietary intake of organophosphorus pesticide residues through vegetables from Kumasi, Ghana," Food and Chemical Toxicology, vol. 46, no. 12, pp. 3703-3706, 2008.

[10] W. J. Ntow, The Use and Fate of Pesticides in VegetableBased Agroecosystems in Ghana, Taylor \& Francis/Balkema, The Netherlands, 2008. 
[11] B. Y. Fosu-Mensah, E. D. Okoffo, G. Darko, and C. Gordon, "Organophosphorus pesticide residues in soils and drinking water sources from cocoa producing areas in Ghana," Environmental Systems Research, vol. 5, no. 1, 2016.

[12] R. Quansah, J. R. Bend, A. Abdul-Rahaman et al., "Associations between pesticide use and respiratory symptoms: a crosssectional study in Southern Ghana," Environmental Research, vol. 150, pp. 245-254, 2016.

[13] A. McDougal and S. Safe, "Induction of 16 $\alpha$-/2-hydroxyestrone metabolite ratios in MCF-7 cells by pesticides, carcinogens, and antiestrogens does not predict mammary carcinogens," Environmental Health Perspectives, vol. 106, no. 4, pp. 203-206, 1998.

[14] S. M. Brander, M. K. Gabler, N. L. Fowler, R. E. Connon, and D. Schlenk, "Pyrethroid pesticides as endocrine disruptors: Molecular mechanisms in vertebrates with a focus on fishes," Environmental Science and Technology, vol. 50, no. 17, pp. 89778992, 2016.

[15] P. T. Agbohessi, I. Imorou Toko, A. Ouédraogo, T. Jauniaux, S. N. M. Mandiki, and P. Kestemont, "Assessment of the health status of wild fish inhabiting a cotton basin heavily impacted by pesticides in Benin (West Africa)," Science of the Total Environment, vol. 506-507, pp. 567-584, 2015.

[16] P. T. Agbohessi, I. I. Toko, V. Atchou, R. Tonato, S. N. M. Mandiki, and P. Kestemont, "Pesticides used in cotton production affect reproductive development, endocrine regulation, liver status and offspring fitness in African catfish Clarias gariepinus (Burchell, 1822)," Comparative Biochemistry and Physiology Part - C: Toxicology and Pharmacology, vol. 167, pp. 157-172, 2015.

[17] B. T. Watermann, T. A. Albanis, S. Galassi et al., "Effects of anti-androgens cyproterone acetate, linuron, vinclozolin, and p,p'-DDE on the reproductive organs of the copepod Acartia tonsa," Journal of Environmental Science and Health - Part A Toxic/Hazardous Substances and Environmental Engineering, vol. 51, no. 13, pp. 1111-1120, 2016.

[18] O. Febvey, J. Schüz, H. D. Bailey et al., "Risk of central nervous system tumors in children related to parental occupational pesticide exposures in three European case-control studies," Journal of Occupational and Environmental Medicine, vol. 58, no. 10, pp. 1046-1052, 2016.

[19] J. Sturza, M. K. Silver, L. Xu et al., "Prenatal exposure to multiple pesticides is associated with auditory brainstem response at 9 months in a cohort study of Chinese infants," Environment International, vol. 92-93, pp. 478-485, 2016.

[20] P. Calatayud-Vernich, F. Calatayud, E. Simó, and Y. Picó, "Efficiency of QuEChERS approach for determining 52 pesticide residues in honey and honey bees," MethodsX, vol. 3, pp. 452$458,2016$.

[21] X. Hou, M. Han, X. Dai, X. Yang, and S. Yi, "A multiresidue method for the determination of 124 pesticides in rice by modified QuEChERS extraction and gas chromatographytandem mass spectrometry," Food Chemistry, vol. 138, no. 2-3, pp. 1198-1205, 2013.

[22] G.-F. Pang, C.-L. Fan, Y.-M. Liu et al., "Multi-residue method for the determination of 450 pesticide residues in honey, fruit juice and wine by double-cartridge solid-phase extraction/ gas chromatography-mass spectrometry and liquid chromatography-tandem mass spectrometry," Food Additives and Contaminants, vol. 23, no. 8, pp. 777-810, 2006.

[23] T. Beyene, M. Woldatsadik, and D. Abi, "Determination of pesticide residues in bee produces honey using gas chromatography mass spectrometry," Excellent Word Journal of Agricultural Science, vol. 1, pp. 1-6, 2016.

[24] T. Rejczak and T. Tuzimski, "QuEChERS-based extraction with dispersive solid phase extraction clean-up using PSA and $\mathrm{ZrO} 2$ based sorbents for determination of pesticides in bovine milk samples by HPLC-DAD," Food Chemistry, vol. 217, pp. 225-233, 2017.

[25] X. Wang, B. Shu, S. Li, Z. Yang, and B. Qiu, "QuEChERS followed by dispersive liquid-liquid microextraction based on solidification of floating organic droplet method for organochlorine pesticides analysis in fish," Talanta, vol. 162, pp. 90-97, 2017.

[26] I.-S. Jeong, B.-M. Kwak, J.-H. Ahn, and S.-H. Jeong, "Determination of pesticide residues in milk using a QuEChERSbased method developed by response surface methodology," Food Chemistry, vol. 133, no. 2, pp. 473-481, 2012.

[27] W. Jia, X. Chu, Y. Ling, J. Huang, and J. Chang, "Highthroughput screening of pesticide and veterinary drug residues in baby food by liquid chromatography coupled to quadrupole Orbitrap mass spectrometry," Journal of Chromatography A, vol. 1347, pp. 122-128, 2014.

[28] K. S. Raghunandan and S. Basavarajappa, "Analysis of multifloral honey of the giant honeybee, Apis Dorsata F., for pesticide residues in Southern Karnataka, India," European Journal of Zoological Research, vol. 2, no. 3, pp. 22-28, 2013.

[29] Ö. Erdoğrul, "Levels of selected pesticides in honey samples from Kahramanmaraş, Turkey," Food Control, vol. 18, no. 7, pp. 866-871, 2007.

[30] M. Shamsipur, N. Yazdanfar, and M. Ghambarian, "Combination of solid-phase extraction with dispersive liquid-liquid microextraction followed by GC-MS for determination of pesticide residues from water, milk, honey and fruit juice," Food Chemistry, vol. 204, pp. 289-297, 2016.

[31] V. Doublet, M. Labarussias, J. R. de Miranda, R. F. A. Moritz, and R. J. Paxton, "Bees under stress: Sublethal doses of a neonicotinoid pesticide and pathogens interact to elevate honey bee mortality across the life cycle," Environmental Microbiology, vol. 17, no. 4, pp. 969-983, 2015. 




The Scientific World Journal
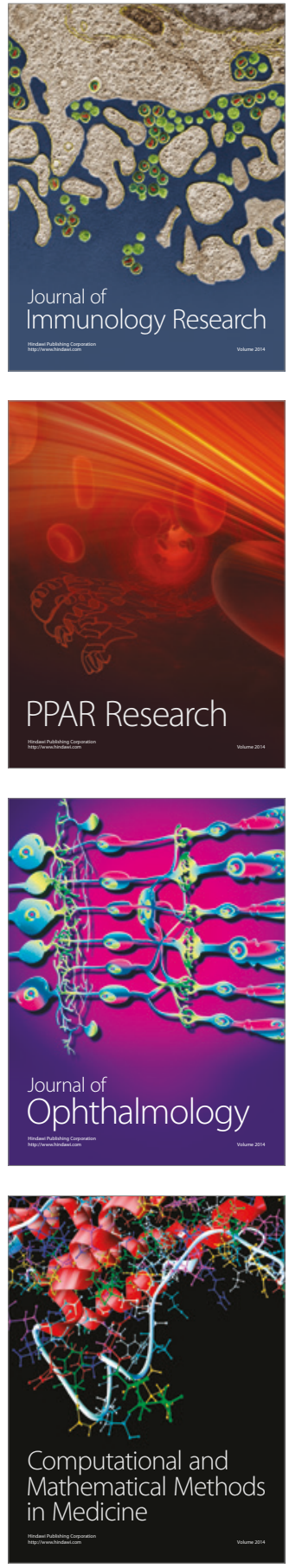

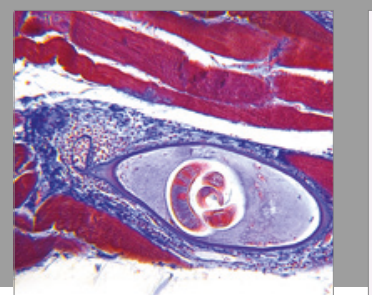

Gastroenterology Research and Practice
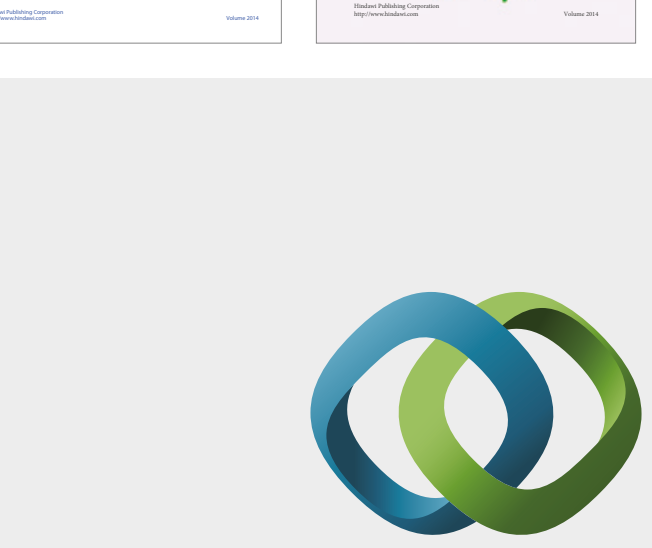

\section{Hindawi}

Submit your manuscripts at

https://www.hindawi.com

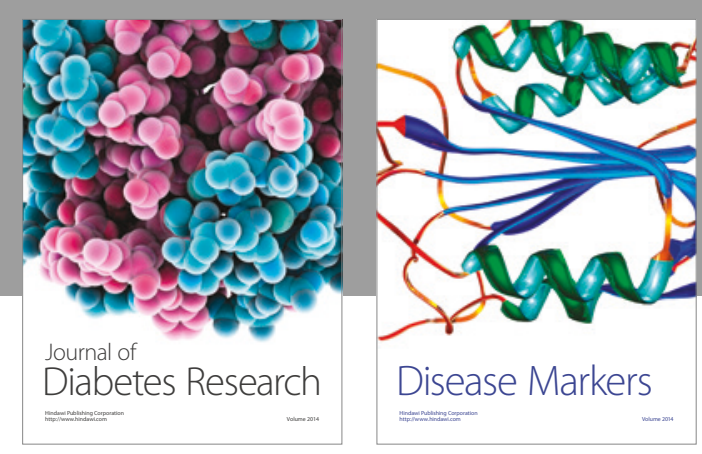

Disease Markers
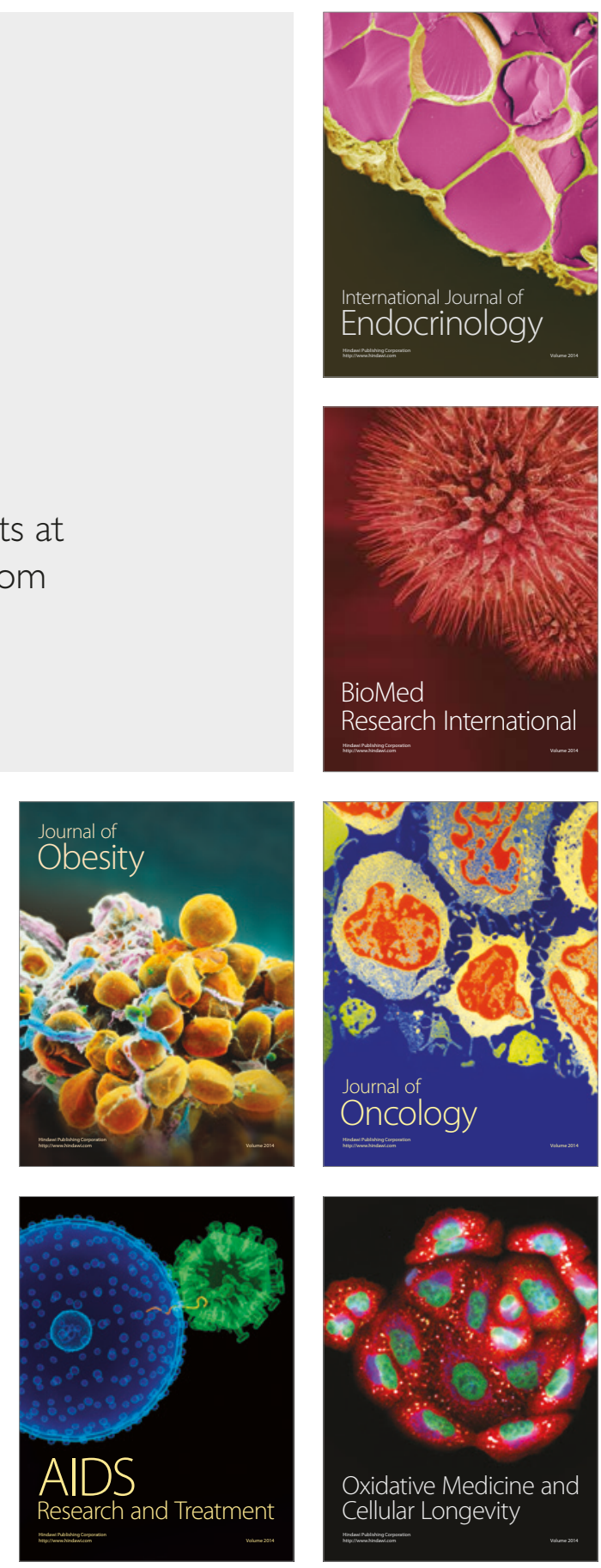